\title{
Exploring the Ethics of Space in Slum Research during COVID-19 through the Lens of Merleau-Ponty
}

\author{
Lily Beth C. Lumagbas ${ }^{1}$ D
}

Received: 2 June 2021 / Revised: 24 August 2021 / Accepted: 26 August 2021 /

Published online: 28 September 2021

(c) National University of Singapore and Springer Nature Singapore Pte Ltd. 2021

\begin{abstract}
COVID-19 modifies a number of social behaviors and standards that we have been following. In slum research, the multifarious issues posed by COVID-19 are not limited to the increased disadvantages of slum inhabitants, but also to the closure of slums as a physical space conducive to understanding the slum dwellers' plight. Their voices are silenced at a time when their narratives are critical for developing policies and initiatives to address their predicament. In this regard, the article will examine Merleau-Ponty's concept of space and then utilize it to create an ethics of space, which is crucial in establishing the viability of virtual space as a creative space that may be used in lieu of traditional slum research. Finally, I discuss the advantages of using virtual space as an alternate space in slum research and how the study might be expanded in the post-COVID era.
\end{abstract}

Keywords Merleau-Ponty $\cdot$ Ethics of space $\cdot$ Slum research $\cdot$ COVID-19

\section{Introduction}

COVID-19 alters many of our ordinary social practices. These changes, mandated by laws and policies, are necessary to counter and curtail the spread of COVID-19. As a result, rather than individuals being in close proximity, a physical gap of one to two meters is recommended. In lieu of a handshake, we now greet one another with fist bumps. Our adapted responses include suspension of mass gatherings, studying and working from home, blended learning, and other similar modifications. People who can afford to adjust to these changes embrace them. Unfortunately, the policies are elitist (Iwuoha and Aniche 2020). People who are living in the slums, even before COVID-19, already experience considerable difficulties in addressing their economic and material needs. They are incapacitated to adapt to the new normal (McFarlane 2020), relegating them to ever-more more precarious and complex

Lily Beth C. Lumagbas

lclumagbas@up.edu.ph

1 Department of Philosophy, University of the Philippines-Diliman, Quezon City, Philippines 
living conditions. Slumdwellers, just like everybody else, are required to follow the mandated health protocols, especially social distancing (Wasdani and Prasad 2020; Walker et al. 2020). For slum dwellers, lockdown means being unable to go out and get informal jobs. Without their income, it means real hunger for their families (McFarlane 2020; Patel et al. 2020).

Slum dwellers are also required to wear a mask and even face shields or else they deal with the risk of being apprehended (Mehta 2020). Unfortunately, without a source of income, they lack the money needed to buy the essentials necessary to comply with the public health protocol (Oxfam 2020). It leaves them extremely reliant on handouts, government help, non-governmental organizations' volunteer works, and other similar assistance coming from civil society to survive.

It is, however, more than that. Numerous slums worldwide have been sealed off to prevent the infection from spreading to other segments of society (World Bank 2020). Their dwellings are regarded as hotbeds of COVID-19. Physical distancing is impossible to maintain in slums due to overcrowding in tiny homes and community spaces (von Seidlein et al. 2021). Furthermore, unsanitary environment (Sahasranaman and Jensen 2021), limited access to clean water (World Health Organization 2020), a lack of waste management (Haddout et al. 2020), and insufficient access to health care (Corburn et al. 2020) encumbers and further increase their risk of contracting COVID-19 (Raju et al. 2021). As a result, COVID-19 exacerbates slum dwellers' marginalization and vulnerability.

Furthermore, many slum dwellers suffer from non-communicable diseases. They are more susceptible, increasing their risk of developing COVID-19 (Tampe 2020). In this scenario, the slum's precarious and fragile existence during the pandemic compels us to research and collect data. It is critical and obligatory to ensure that policies addressing their situation are responsive to their actual circumstances and needs, but how?

The purpose of this paper is to explore the ethics of space in relation to slums and slum research during the COVID-19 pandemic. How do we create an inclusive space in slum research in a situation where people's lived spaces are deemed hotbeds of infection? The study's analysis is based on Merleau-Ponty's concept of space. It is a watershed moment in ethics, as slums serve as the space for slum research. Additionally, it will assess the viability of establishing a creative space in virtual reality as a feasible alternative for slum research. Finally, I will describe the advantages of virtual space.

\section{Space in Slum Research: The Slums}

Slum spaces are considered the actual living spaces of people living in a condition of abject poverty. Their physical environment and circumstances are defined by overcrowding, limited restricted access to clean water, a lack of sanitation, negligible and inadequate waste management, unsafe housing, a hazardous environment and inadequate access to healthcare (UN-Habitat 2015). It is slum space. Understanding the slum space is crucial in comprehending the human condition of the people residing in the slums the slum dwellers. Examining their predicament entails grasping the reality of their lived space - the slums. As a result, slums as lived spaces are vital in slum research. Unfortunately, visiting slums poses a risk to both the slum dwellers and the researchers during 
the COVID-19 pandemic. We cannot put anyone's safety and health at risk. It does, however, pose a different threat - the stifled and continued marginalization of their voices as slum dwellers space is viewed as a hotbed of infection.

\section{Merleau-Ponty On Space}

Merleau-Ponty's (MP) Phenomenology of Perception $(P h P)$ delves into the centrality of our perceptual consciousness in our existential structure. MP demonstrated how our being-in-the-world does not require us to surrender and reduce our humanity to pure materiality-physicality or abstracted intellectualism. Rather than that, he elevated human beings to the status of natural subjects in the natural world (Liu 2009, 138). MP accomplished this by focusing his analysis on the intricate connection between the body, consciousness, Others, and the World. MP's phenomenology of space clarifies this complex relationship, though his exposition was limited compared to his analysis of perception and consciousness (Liu 2009).

Space is critical in comprehending Merleau-Ponty's being-in-the-world. It enables the simultaneity of experience as it is the necessary field or ground where the perceptual something belongs, "the perceptual something is always in the middle of some other thing, it belongs to a field" (Merleau-Ponty 2012, 312). As such, space is not merely a background to human existence. We are inextricably and intrinsically linked to the world through our body, to the point that there is "solidarity between man and the world" (Merleau-Ponty 2012, 304) and that "there will be no space at all for me if I had no body" (Merleau-Ponty 2012, 117). In this sense, space becomes both the point and the horizon. Space is the point in which the body is physically connected and anchors itself to the world whereas it is the horizon because space is where interaction and relationships become possible and realized.

Furthermore, Merleau-Ponty distinguished two types of spaces: bodily space (situated space) and objective space (positional space). MP refers to objective (positional) space as the space where objects are found, events happen, and it can be described by height, weight, depth, and width. On the other hand, in bodily (situated) space, MP emphasized the critical role of the engagement of the body. The engagement of the body signifies the following: First, the body serves as the determinate point in the world, so much so that Merleau-Ponty $(2012,117)$ states, "no space at all for me if I had no body". Second, the body to be a determinate point in the world implies it anchors, shares, and connects with the world's objective reality. The body, however, is not passive. It moves, engages, and interacts simultaneously and constantly with the world. It communicates with the world and establishes connections with others. In this sense, "Space is motility" (Merleau-Ponty 2012, 106).

Space is the person's place of movement. It becomes a continuum of action, movement, response, and simultaneity as the entire place and space itself become a part of the person. Due to the truism that movements occur within the world, spaceplace alteration occurs. The person acts and moves in space while also manifesting the person's actual position as an inhabitant of the world. Hence, the world is opening, creating room for the person's movement to transpire here-in this particular place. It is essential to note that movement in space-place is not simply about 
being able to move. People's actions and movements are responses for "our sense of space testifies to the fact that experience is a movement open to the world" (Morris 2004, 175). It draws attention to a unique place in universal space. For example, even when many people desired to get out of their homes during the COVID-19 lockdowns, they did not. The strict enforcement of restrictions on where and how people can travel and move is intended to protect people and contain the spread of infection. As a result, the response was to abstain from going outside.

Merleau-Ponty shifts our understanding of space by emphasizing the distinctive characteristics of the content of lived space in comparison to that of traditional space. The contents of the conventional view of space are perceptible objects. They are external to the perceiver and exist independently of the perceiver. The objects are homogenous in this sense. As such, space is made up of disparate, perceptible objects.

On the other hand, lived space is made up of embodied beings engaged in the world. Their engagement occurs as a result of their rootedness and anchoredness to the world, which enables them to move about and experience it. According to MP, lived space is a necessary component of a person's unit of experience. As such, it consists of heterogeneous natural subjects on the natural World (Liu 2009), creating "solidarity between the man and the world" (Merleau-Ponty 2012, 304). You will find subjects who are communicating, engaging, interdependent, and interacting in lived space. While in space, you will encounter independent, non-interacting objects.

Additionally, Merleau-Ponty's notion of space reveals critical points about his ethics. The following are these points. First, the locus of a person's action-movement is her space-place. The person's actions and movements are realized as a result of his or her inhabiting the world. They are in the world, embedded in it. The world is the fertile ground and field for their actions and movements. Second, all human beings inhabit the world. They share in the universal space as beings-in-theworld. So, regardless of how imperfect our gaze is, it is in this shared universal space that we perceive others. Third, in conjunction with the capacity of human beings to express emotions and thoughts through speech, the shared universal space serves as a point of convergence for the realization of expressing and sharing our individual experiences. As a meeting point, the universal space provides the following: (a) the seeing of other people, (b) a constraint on our movement due to the seen presence of others, (c) openness to movement, and (d) a possibility of connecting with others. In this sense, universal space is not transcendental and immaterial; instead, it is our shared and lived world. Finally, fourth, space-place is a critical factor in determining how we respond to our human condition. It is not a separate dimension of our lived experiences.

These four points allow us to see space-place as a material point in the world, thereby, establishing a connection between our situatedness and shared universal space. It leaves open the possibility of connection between and among human persons as they act, move, and respond to their situatedness. Space-places are lived spaces. This perspective on space is what elevates it from a material or ontological discourse to an ethical one.

The ethics of space is predicated on the concept of lived space (Morris 2004). It is rooted in the encounters people have in the space-place in which they find 
themselves. This is not abstracted ethics; rather it is about lived ethical dilemmas that arise as we negotiate our shared space with Others. As Morris (2004) noted, the ethics of space is not about the specific details of the content of space ethics. Instead, it concerns people inhabiting the world and the possibility of ethical living in our shared space.

\section{Merleau-Ponty, Ethics of Space, Slums, and Slum Research}

Merleau-Ponty introduced us to the concept of space as a necessary field or ground for human movement and action in the world. It is a lived space, not an abstracted one. The ethics of space, in this regard, compels us to contemplate the lived dynamics of ethics. Lived spaces are points of entry in the universal shared space for people inhabiting the world, and it is there that the challenge of ethical living arises. The fundamental question of how to live well in our shared and lived space must be addressed. From this vantage point, slums as lived spaces compel us to meet the slum dwellers in their place. We discover slum reality as genuinely lived spaces amid human progress by seeing, smelling, and touching their lived condition. It is real. In this regard, autonomy, regard for dignity, and human rights are just a few of the ethical issues that may arise as we enter their lived space.

When the natural subjects of the natural world-us-come together to inhabit a particular place, the lived space becomes the shared space. At this point, we come face-to-face with the ethical dilemmas of justice and harmony. In this regard, slums pose a more significant challenge to our notion of situated space conducive to meeting others. When lived and shared spaces become a source of exclusion and stigma (a hotbed for infection), contradictions arise. It is a paradox. Lived and shared space is intended to be a point of encounter and engagement. However, it has been transformed into a zone of non-engagement, relegating the Other to the category of something to be avoided.

In the condition of the COVID-19 pandemic, slum research has to forego the opportunity of encountering slum dwellers in slums. Instead, research seeking to investigate the lived experied of persons in these spaces must be creative, innovative, and unconventional in their approach to gather information about the plight of the persons.

\section{Virtual Space: Addressing their Condition and Arena for their Voice}

Creativity creates opportunities. Being creative, innovative, and unconventional in slum research entails departing from established methods in doing slum research. By incorporating virtual space into slum research during a pandemic, many slum dwellers gain access to new spaces. Although this is already being done, use of virtual space, simulation, online and telephone interviews, social media, drones for mapping, and online focus group discussions are utilized in slum research to a limited extent. It is past time for us to truly open up the virtual space in slum. This strategy has a number of advantages. 
1. Practical. Many people living in slums own cell phones. They use their devices to make connections with other people in order to find work and engage with others in a range of activities. Mobile phones provide access to various facets of urban life (Sarin and Jain 2009). Conducting interviews and focus group discussions via messenger or Viber enables the researcher to see their predicament in real-time without putting themselves and the researchers in danger.

2. Empowering. Many slum dwellers, particularly the younger residents, are familiar with the use of social media via their phones. It is an opportunity for them to share their experiences as they navigate the challenges of the pandemic. Additionally, they will be able to communicate their experiences as they unfold. As a result, their narratives are rich and thick descriptions of what is happening. Exploring this medium allows a full range of experiences to be shared.

3. An Arena. Virtual space provides a platform for slum dwellers' voices to be heard via their mobile connections and social media. At this point, when their narratives are critical for developing policies and programs, their shared stories will be extremely beneficial, as they will serve as evidence of their actual lived conditions. Thus, the effects of the pandemic on their space as a lived place made smaller by the disease and associated restrictions become more accessible to researchers and policy-makers and planners. As a result, the creation of this virtual space can result in more responsive programs designed to change the lived space, which is precisely what they need.

4. Creative space. The use of technology in slum research is an opportunity to meet the slum residents within slum conditions. It creates the chance to meet, act, and move as they respond to their condition. Thus this creation of virtual spaces allows researchers to continue work in more creative ways when, otherwise, the opportunity to research lived space would otherwise be lost because of the conditions of the pandemic, especially as it affects slums and the people who live there.

While the virtual space allows for the continuation of slum research in the face of the pandemic, some ethical concerns are raised. Virtual space's anonymity creates a risk for fraud and deception. Honesty and integrity are two of the ethical issues that arise in the virtual world. Nobody knows who you are; thus, in virtual space, masquerading and portraying your imagined self as real becomes easy. Another ethical concern is the heightened blurring of the private-public divide, particularly in virtual space - at what point does sharing cease to be sharing and exhibitionism and voyeurism begin? (McNeill and Zuern 2015). Additionally, an increased sense of vulnerability as a result of surveillance and a lack of control over shared memoirs in the virtual space raises ethical concerns. Finally, there is the issue of access, which is a matter of justice and equity. Communities with limited resources, such as slums, have limited access to technology that supports virtual space, leaving many members of these communities behind in the face of rapid technological advancements. Not all voices will be heard. These are just a few of the ethical issues that have been raised in virtual space. The list is not exhaustive, necessitating a more in-depth examination of this particular subject.

Despite these limitations and issues, virtual space as a creative space in slum research ultimately creates a new place for slum dwellers. Virtual space can be a 
liberating and empowering environment that can respond to their needs and struggles during these trying times.

\section{Conclusion}

As COVID-19 exacerbated the already precarious lives of slum dwellers and the pandemic effectively shut down the slums, Merleau-Ponty's ethics of space enables us to become and remain ethical in our shared universal space, even in times of peril. Furthermore, the need for an alternate space becomes critical as we attempt to hear and comprehend slum dwellers' current predicament as they negotiate COVID-19. The study proposes the use of creative space in the manner in which it is constructed and observed in virtual space. It serves as a de facto alternate meeting location. It is exploratory in nature. As a result, it is necessary to clarify the concepts in play and to identify situations in which they can be applied responsibly and studied further to promote ethically sound research that ultimately can be used to improve the lives of persons living in slum conditions.

\section{References}

Corburn, Jason, David Vlahov, Blessing Mberu, Lee Riley, Waleska Teixeira Caiaffa, Sabina Faiz Rashid, Albert Ko, Sheela Patel, Smurti Jukur, Eliana Martínez-Herrera, Saroj Jayasinghe, et al. 2020. Slum health: Arresting COVID-19 and improving well-being in urban informal settlements. Journal of Urban Health 97 (3): 348-357. https://doi.org/10.1007/s11524-020-00438-6.

Haddout, S., K.L. Priya, A.M. Hoguane, and I. Ljubenkov. 2020. Water scarcity: A big challenge to slums in Africa to fight against COVID-19. Science \& Technology Libraries 39 (3): 281-288. https://doi. org/10.1080/0194262X.2020.1765227.

Iwuoha, Victor Chidubem, and Ernest Toochi Aniche. 2020. COVID-19 lockdown and physical distancing policies are elitist: Towards an indigenous (Afro-centred) approach to containing the pandemic in sub-urban slums in Nigeria. Local Environment 25 (8): 631-640. https://doi.org/10.1080/13549 839.2020.1801618.

Liu, Shengli. 2009. Merleau-Ponty's Phenomenology of Space: Preliminary Reflection on an Archaeology of Primordial Spatiality. In The 3rd BESETO Conference of Philosophy, Session 5, 131-140.

McFarlane, Colin. 2020. The urban poor have been hit hard by coronavirus. We must ask who cities are designed to serve. The Conversation, 3 June 2020. https://theconversation.com/the-urban-poor-havebeen-hit-hard-by-coronavirus-we-must-ask-who-cities-are-designed-to-serve-138707. Accessed 15 Feb 2021.

Mehta, Poonam. 2020. The Asian region and COVID-19: approaches and gaps in controlling the virus. Asian Education and Development Studies 10 (2): 185-197. https://doi.org/10.1108/ aeds-05-2020-0090.

Merleau-Ponty, Maurice. 2012 [1945]. Phenomenology of Perception. Translated by Donald A. Landes. Abingdon: Routledge.

McNeill, Laurie, and John David Zuern. 2015. Online lives 2.0: Introduction. Biography 38 (2): v-xlvi. https://doi.org/10.1353/bio.2015.0012.

Morris, David. 2004. The Sense of Space. New York: State University of New York Press.

Oxfam. 2020. Dignity not Destitution: An 'Economic Rescue Plan for All' to tackle the Coronavirus crisis and rebuild a more equal world. Oxfam Media Briefing, 9 April 2020. https://www.oxfam.org/en/ research/dignity-not-destitution. Accessed 10 Sep 2021. 
Patel, J.A., F.B.H. Nielsen, A.A. Badiani, S. Assi, V.A. Unadkat, B. Patel, et al. 2020. Poverty, inequality and COVID-19: The forgotten vulnerable. Public Health 183: 110-111. https://doi.org/10.1016/j. puhe.2020.05.006.

Raju, Emmanuel, Anwesha Dutta, and Sonja Ayeb-Karlsson. 2021. COVID-19 in India: who are we leaving behind? Progress in Disaster Science 10: 100163. https://doi.org/10.1016/j.pdisas.2021.100163.

Sahasranaman, Anand, and Henrik Jeldtoft Jensen. 2021. Spread of COVID-19 in urban neighbourhoods and slums of the developing world. Journal of the Royal Society Interface 18 (174): 20200599. https://doi.org/10.1098/rsif.2020.0599.

Sarin, Ankur, and Rekha Jain. 2009. Effect of Mobiles on Socio-Economic Life of the Poor. Working Paper No. 2009-02-05. Ahmedabad: Indian Institute of Management. https://ideas.repec.org/p/ess/ wpaper/id1984.html. Accessed 10 Sep 2021.

Tampe, Tova. 2020. Potential impacts of COVID-19 in urban slums: addressing challenges to protect the world's most vulnerable. Cities \& Health. https://doi.org/10.1080/23748834.2020.1791443.

UN-Habitat. 2015. Habitat III issue papers: 22-informal settlements. New York: UN-Habitat. https:// unhabitat.org/habitat-iii-issue-papers-22-informal-settlements. Accessed 10 Sep 2021.

von Seidlein, Lorenz, Graham Alabaster, Jacqueline Deen, and Jacob Knudsen. 2021. Crowding has consequences: prevention and management of COVID-19 in informal urban settlements. Building and Environment 188: 107472. https://doi.org/10.1016/j.buildenv.2020.107472.

Wasdani, Kiscinchand Poornami, and Ajnesh Prasad. 2020. The impossibility of social distancing among the urban poor: The case of an Indian slum in the times of COVID-19. Local Environment 25 (5): 414-418. https://doi.org/10.1080/13549839.2020.1754375.

Walker, Patrick, Charles Whittaker, Olivia Watson, Marc Baguelin, Peter Winskill, Arran Hamlet, et al. 2020. The impact of COVID-19 and strategies for mitigation and suppression in low- and middleincome countries. Science 369 (6502): 413-422. https://doi.org/10.1126/science.abc0035.

World Bank. 2020. Poverty and Shared Prosperity 2020. https://www.worldbank.org/en/publication/ poverty-and-shared-prosperity. Accessed 21 Jan 2021.

World Health Organization. 2020. Access to water, sanitation and hygiene should be part of basic human rights. Geneva: World Health Organization.

Publisher's Note Springer Nature remains neutral with regard to jurisdictional claims in published maps and institutional affiliations. 